\title{
LA CIENCIA COMO TECNOLOGÍA EN JOHN DEWEY
}

J. MIGUEL ESTEBAN

DEPARTAMENTO DE FILOSOFÍA

UNIVERSIDAD AUTÓNOMA DEL ESTADO DE MORELOS

"Sólo el conocimiento que es fruto de la tecnología puede generar a su vez tecnología"

John Dewey (LW 6:67)

\section{Tecnología, pragmatismo y crítica de la cultura: Dewey, Putnam, Rorty}

Sociólogos e historiadores no suelen ser remisos a la hora de emitir dictámenes implacables sobre la producción de los filósofos anglosajones de la tecnología: en su opinión, cuando éstos se afanan en establecer una nítida separación analítica entre ciencia y tecnología, aferrándose a una ulterior distinción tripartita entre contexto de descubrimiento, contexto de justificación y contexto de aplicación, todo lo que vuelven a ofrecernos es otra idealización simplista de la ciencia: una idealización que adopta sin más antiguas concepciones positivistas, cuando no modelos explicítamente nomológico-deductivos de las teorías científicas. Pinch y Bijker llegan a afirmar que la literatura sobre la filosofía de la tecnología es del todo decepcionante, de modo que prefieren suspender su juicio hasta que "los filósofos propongan modelos más realistas de la ciencia y la tecnología". ${ }^{1}$ El propósito de estas páginas es presentar el instrumentalismo naturalista de John Dewey, esto es, aquella caracterización "más realista" de la ciencia como tecnología que el pensador norteamericano desarrollara a lo largo de la primera mitad del siglo xx, es decir, precisa y no casualmente cuando los modelos positivistas alcanzaron su apogeo.

A mi modo de ver, el instrumentalismo naturalista de John Dewey no sólo ofrece sugerentes ventajas a la hora de abordar algunos problemas de la filosofía de la ciencia, sino que también permite bosquejar una caracterización

1 W.E. Bijker y T. Pinch, "The Social Construction of Facts and Artifacts", en The Social Construction of Technological Systems, W.E. Bijker, T.P. Hughes y T. Pinch (eds.), MIT Press, Cambridge, 1987, p. 19. 
alternativa del pragmatismo americano como crítica de la cultura, locución que el propio Dewey utilizó repetidas veces para definir su propio quehacer filosófico. De modo que, en primer lugar, señalaré los rasgos distintivos de mi concepción de la filosofía de John Dewey, para más tarde ahondar en tesis mucho más concretas sobre mi interpretación deweyana de la ciencia como tecnología.

Durante las dos últimas décadas hemos presenciado diversos intentos de rehabilitación filosófica de la noción de "pragmatismo", durante muchos años asociada con toda suerte de bajezas humanas $y$, en particular, con cierto maquiavelismo corruptor de la tarea crítica de la filosofía. Dos de las más célebres y controvertidas rehabilitaciones del pragmatismo dentro de la llamada tradición analítica son las de Hilary Putnam y Richard Rorty. Uno y otro se reclaman herederos de John Dewey y apelan reiteradamente al topos deweyano de "crítica de la cultura". Ahora bien, lo que Rorty y Putnam entienden por tal noción son cosas harto distintas.

Para Rorty, la crítica de la cultura no está bajo la tutela de la filosofía (ésta no es "guardián e intérprete" de la cultura, por emplear la célebre locución de Habermas), sino que puede realizarse desde la religión, la literatura, el periodismo, las ciencias, las artes. . desde cualquier parte. Es más, para Rorty, las argumentaciones trascendentales convierten el elemento normativo de la crítica de la cultura en algo absolutamente estéril. ${ }^{2}$ Si Peirce representa la facción kantiana del pragmatismo, más próxima al sentido de crítica defendido por la pragmática trascendental de Apel y la teoría de la acción comunicativa de Habermas, Dewey es para Rorty un hegeliano naturalizado. Según Rorty, "el gran mérito de Dewey fue haber permanecido lo suficientemente hegeliano como para no pensar que la ciencia natural tenga un acceso interior a las esencias de las cosas, al tiempo que se mantenía

2 En una conversación mantenida en Girona con Richard Rorty en junio de 1996, este autor dio una buena explicación de por qué las batallas ganadas por la crítica no son precisamente aquéllas en las que se esgrimen argumentaciones trascendentales à la Frankfurt: "A la hora de ejercer la crítica, creo que sería mejor atender a las consecuencias de la postura criticada y no ir en busca de presuposiciones o de condiciones de posibilidad supuestamente infringidas. Sería más útil formular preguntas de índole práctica como: '¿Puede imaginar cómo llevar a cabo consecuentemente su programa?' Al cuestionar la credibilidad de su postura mediante una pregunta de este tipo, la otra persona puede contestar: 'Lo haré de tal y cual modo o en tales y cuales condiciones, con tales y cuales restricciones, etc. [...]' o 'Éste es el contexto en el que desarrollaré mi programa'. Mientras que la acusación de autocontradicción bloquea el diálogo, las últimas preguntas pueden dar pie a una argumentación más razonable con nuestro oponente, discutiendo si existe o no ese contexto para desarrollar su posición, si existe o no algún otro mejor, etc. [...] Pero pienso que es inútil, además de descortés, soltarle a alguien que no acaba de entender su propia práctica, o acusarlo de haber incurrido en una autocontradicción performativa o realizativa... " (J. Miguel Esteban, "Cómo ser un buen pragmatista. Conversación con Richard Rorty", Debats, no. 61, 1998.) 
lo suficientemente naturalista como para pensar en los seres humanos en términos darwinianos". ${ }^{3}$

Pienso que esta interpretación de Rorty dista de ser tan original como pretende. Sin ir más lejos, H.S. Thayer titulaba uno de los mejores apéndices de su libro Meaning and Action: A Critical History of Pragmatism, "Dewey: Continuity/ Hegel-Darwin". ${ }^{4}$ Otros muchos intérpretes pragmatistas han reivindicado la figura de Dewey como un hegeliano naturalizado, algo que no puede sorprendernos mucho, al menos si leemos "From Absolutism to Experimentalism", la autobiografía intelectual que el propio Dewey escribiera a finales de los años veinte. ${ }^{5}$ Pero ese supuesto hegelianismo darwinista no convierte a Dewey en el adalid de la cultura posfilosófica que Rorty defiende, como tampoco hace que su crítica deje a la cultura sólo con esperanzas infundadas (groundless hopes). El punto ha sido largamente debatido por muchos autores, y no tiene caso repetir una crítica en la que estoy básicamente de acuerdo. ${ }^{6}$ Lo que sí deseo señalar aquí es que, dada su

3 Richard Rorty, La filosofía y el espejo de la naturaleza, trad. de J.F. Zulaica, Cátedra, Madrid, 1979, p. 327.

4 Véase H.S. Thayer, Meaning and Action. A Critical History of Pragmatism, Hackett, Indianápolis y Cambridge, 1981, pp. 460 y ss.

5 Teniendo en cuenta esta evidencia documentada, y no la reapropiación rortiana de Dewey o de Hegel (cuyo mérito, según Rorty, residía en buena parte en ser "el paradigma de la capacidad del ironista de explotar las posibilidades de una redescripción abundante", en ser el iniciador de una serie de hábiles redescripciones de léxicos intraducibles pero vertiginosamente reemplazables ad libitum, véase $R$. Rorty, Contingencia, ironía y solidaridad, Paidós, Barna, 1991, p. 96), he de reconocer que sí considero a Dewey un hegeliano naturalizado. "La familiaridad con el pensamiento de Hegel ha dejado un permanente depósito en mi pensamiento [...] Mis estudios filosóficos anteriores habían sido una especie de gimnasia intelectual. La síntesis hegeliana entre sujeto y objeto, materia y espíritu, lo divino y lo humano, no era, sin embargo, una mera fórmula intelectual; era como un gran desahogo, una liberación. El tratamiento hegeliano de la cultura humana, de las artes y las instituciones, implicaba la misma eliminación de muros divisorios e inamovibles, y me resultaba particularmente atractivo" (LW 5:153). [Todas las citas de Dewey irán especificadas según la edición crítica de su obra completa publicada por la Southern Illinois University Press, bajo la dirección editorial de Jo Ann Boydston: The Early Works, 1882-1898, 5 volúmenes; The Middle Works, 1899-1924, 15 volúmenes; The Later Works, 1925-1953, 17 volúmenes. Citamos con la abreviatura (EW, MW, LW) seguida de la paginación en la edición crítica.] Por cierto que la "naturalización" del idealismo alemán por parte del pragmatismo americano aparece explícitamente en la obra de Dewey (véase MW 2:251-252 y MW 6:94) Al parecer, Dewey tomó muy en serio la obra de D. Ritchie, Darwin and Hegel (Swan Sonnenschein and Co., Londres, 1893), habida cuenta de las numerosas referencias que a tal libro hace. Desgraciadamente, tampoco puedo demorarme aquí en este punto. Con todo, sobre el hegelianismo de Dewey, véase más adelante, nota 22 y epígrafe IV de este mismo artículo. Véase también, "Pragmatismo consecuente", la introducción que escribí en mi edición de J. Dewey: Liberalismo y acción social y otros ensayos (Alfons el Magnànim, Valencia, 1996).

6 Véase "Symposium on Rorty's Consequences of Pragmatism", publicado en Transactions of the Charles Peirce Society, vol. 21, no. 1, 1985. La reapropiación rortiana de Dewey está 
insistencia en dicha groundless hope, Rorty no parece haber profundizado en el importante papel que Dewey asigna a la filosofía de la tecnología, ni a la función de la tecnología como sujeto y objeto de la crítica de la cultura. ${ }^{7}$

El caso de Hilary Putnam, por qué no decirlo, más cercano al Habermas de Ciencia y técnica como ideología y al Apel defensor de la prima philosopia, ${ }^{8}$ es algo más complejo. Para Putnam, naturalizar el hegelianismo sólo significa sacrificar la noción de "verdadera racionalidad" en aras de un "relativismo cultural" que deslegitima y enmudece la crítica. ${ }^{9}$ Putnam, por el contrario, ha abanderado un programa fuerte de defensa y renovación de la específica función normativa que primariamente debe cumplir la filosofía. Y en su opinión, el elemento normativo de la crítica de la cultura no puede ser naturalizado. Resulta pues comprensible que Putnam aproxime a Dewey a Kant y no a Darwin. Mi interpretación del pensamiento de Dewey y de su filosofía de la tecnología comienza pues en negativo, criticando esta aproximación kantiana.

En Il pragmatismo: una questione aperta Hilary Putnam ya no oculta sus esfuerzos por entroncar el pensamiento de John Dewey con la tradición del kantismo. Si bien sus intentos por aproximar la tradición pragmatista y la tradición kantiana han ido reiterándose desde Razón, verdad e historia,

fuertemente sesgada, y es difícil hallar un lector de Experience and Nature que, tras concluir su lectura, sienta haber sido sometido a un tratamiento terapéutico antimetafísico, tal y como pretende Rorty en Consecuencias del pragmatismo (trad de J. Miguel Esteban, Tecnos, Madrid, 1994), pp. 39 y ss. Aunque, para ser justos, habría al menos que citar una virtud de la interpertación rortiana de Dewey como hegeliano: su antifundamentalismo. Al menos Stanley Rosen aboga por ello: "Lo importante es señalar que el sistema hegeliano no es fundamentalista [...] De ahí que quepa concluir que si, en nuestro tiempo, hay una empresa legítima llamada filosofía, debe proceder en ausencia de fundamentos [...] de ahí al abandono de la filosofía hay sólo un paso. Es mérito de Rorty haberlo entendido así" (The Ancient and the Moderns, Yale, New Haven, 1990, p. 188). Ese último paso es el que, en nuestra opinión, no está tan claro: ¿Acaso pretende Rosen que no hay filosofía sin aspiraciones fundamentalistas? Véanse los artículos de Sleeper y Eden en el citado "Symposium on Rorty's Consequences of Pragmatism", además del capítulo final del libro de L. Hickman, John Dewey's Pragmatic Technology (Indiana University Press, Bloomington, 1991).

7 Sólo en el segundo volumen de los Philosophical Papers de Rorty (Ensayos sobre Heidegger y otros, trad. de Jorge Vigil, Paidós, Barna, 1993, pp. 74-75) aparece una breve mención a la concepción deweyana de la tecnología, en una analogía de tintes poéticos. Véase mi nota al prefacio de Consecuencias de pragmatismo, op. cit., p. 16. Siento no poder extenderme en este punto, que exigiría una revisión de la relación Dewey-Heidegger que Rorty propone a partir de las obras de M. Okrent, Heidegger's Pragmatism (Cornell UP, Ithaca, NY, 1988) y R. Brandom "Heidegger's Categories in Being and Time" (Monist, no. 60, 1983). Pero véase de nuevo L. Hickman, op. cit., p. 199, para un contraste entre los dos filósofos.

8 Véase Razón, verdad e historia, trad. de J. Miguel Esteban, Tecnos, Madrid, 1988, particularmente el capítulo 8, en su nota 1.

9 Veáse H. Putnam, "Why Reason Can't Be Naturalized", en Realism and Reason, Phil. Papers, vol. 3, Cambridge University Press, Cambridge, 1983. 
en sus lezioni italiani la intención moralizadora con la que Putnam efectúa dicha aproximación es bien explícita: "la estrategia kantiana", escribe Putnam,

se reitera en los escritos de John Dewey, aunque éste le priva de apriorismo. [...] En un contexto de este tipo, [como el] suscrito por John Dewey, puede leerse que la actividad primaria de la filosofía debería ser la crítica de la cultura. A pesar de sus excesos metafísicos, la filosofía de Kant pretendía ser una crítica de la cultura; un esbozo o esquema para una sociedad esclarecida, en condiciones de progresar hacia un estado en el que reinaría la justicia social. ${ }^{10}$

Ahora bien, por loables que sean las intenciones de Putnam a la hora de establecer la filiación kantiana de la filosofía como crítica de la cultura en Dewey, pienso que dicha aproximación sólo puede llevarse a cabo olvidando buena parte de las tesis sustantivas de ambos autores. A mi modo de ver, la "sociedad esclarecida" a la que conduciría la filosofía de Kant es bien distinta de la que orienta la "crítica de la cultura" deweyana. En la primera, el conocimiento técnico o instrumental resulta indiferente para dotar normatividad a la acción humana. En la segunda, omitir ese conocimiento en la deliberación y la acción es simplemente un purismo irresponsable.

Pero hay.otra diferencia que resulta de mayor calado si cabe y que, por fin, me servirá para una primera aproximación a la crítica deweyana de la tecnología: mientras que para el Kant de la Grundlegun la justicia es inconcebible sin la escisión entre humanidad y naturaleza, para Dewey esa separación es precisamente fuente de irresponsabilidad e iniquidad.

En este escrito esbozaré una reconstrucción del pensamiento de Dewey que permita entrever cómo la crítica de la cultura sólo es posible si no marginamos de ésta (como pienso hizo el Kant de la Fundamentación de la metafísica de las costumbres) ${ }^{11}$ el conocimiento de la construcción tecnológica del mundo humano. Con dicha lectura pretendo mostrar que, pese al punto descalificador habitualmente unido al pragmatismo, éste se ha-

10 H. Putnam, Il pragmatismo: una questione aperta, trad. de Roberto Rosaspini, Laterza, Roma, 1992; Gedisa, Barcelona, 1999, p. 67.

11 Quiero insistir en este punto, pues tanto en la Crítica del juicio, como en la Paz perpetua y en las Ideas para una historia universal en sentido cosmopolita, Kant parece abrazar una idea de representabilidad sistemática de una técnica de la naturaleza en analogía con el arte humano. "Natura daeadala rerum", afirmará Kant en la Paz perpetua, pareciendo dar pie a la imitatio naturae de las artes mecánicas. Sobra decir que esa concepción escatológica de Naturaleza, aunque se conciba la tecnología como la astucia de la razón histórica, al modo hegeliano, es del todo ajena al instrumentalismo naturalista de Dewey. 
lla mucho más distanciado del nihilismo tecnológico ${ }^{12}$ que el formalismo kantiano. Pero pasemos ahora a otras tesis mucho más específicas de mi interpretación de la ciencia como tecnología en Dewey - tesis que, por lo demás, pienso que avalan una interpretación alternativa de la filosofía de la tecnología de Dewey como crítica de la cultura.

Como ya había adelantado, el instrumentalismo de Dewey ofrece algunas ventajas a la hora de abordar ciertos problemas de la filosofía de la ciencia y de la tecnología. Desde el punto de vista de la filosofía de la ciencia, la ventaja decisiva reside en que su modelo logra preservar nuestra intuición realista con respecto a la actividad científica, haciendo pivotar ésta sobre la construcción tecnológica de fenómenos experimentales. No es casualidad que Ian Hacking, conocido defensor de las tradiciones experimentales -y autor de la célebre frase "si pueden rociarse, son reales" - reivindique enfáticamente la figura de Dewey como constructivista:

El mundo y nuestra representación del mismo parecen convertirse, en las manos de Dewey, en algo muy parecido a un constructo social [...] Se burlaba de lo que él llamaba la teoría del conocimiento del espectador. Decía que éste era el resultado de la existencia de una clase acomodada que pensaba y escribía filosofía, opuesta a una clase de empresarios y trabajadores que no tenía tiempo para sólo ver. Mi propia opinión, a saber, que el realismo es un asunto de intervenir en el mundo, más que de representarlo en palabras y pensamiento, ciertamente le debe mucho a Dewey. ${ }^{13}$

Y lo cierto es que la filosofía deweyana anticipa algunos de los argumentos que han acabado con la primacía que la teoría disfrutó durante largo tiempo en la filosofía de la ciencia y de la tecnología.

Con todo, la figura de John Dewey no suele aparecer en los manuales al uso de filosofía de la tecnología. Sólo Mitcham, hasta donde sé, dedica unos párrafos a Dewey en Thinking Through Technology. ${ }^{14}$ Varias razones

12 Tomo la expresión nihilismo tecnológico de Rorty, quien a su vez la emplea al describir la crítica de Heidegger a Dewey. Véase Richard Rorty, "Superando la tradición: Heidegger y Dewey", en Consecuencias del pragmatismo, op. cit., pp. 99 y ss.

13 Ian Hacking, Representar e intervenir, trad. de Sergio Martínez, unAM-Paidós, México, 1997 , p. 83.

14 Y eso, sospecho, bajo el influjo de John Dewey's Pragmatic Technology (Indiana University Press, Bloomington, 1991), de Larry Hickman, colega de Mitcham en la Society for Philosophy and Technology. Es a Hickman a quien debemos el actual interés despertado por la filosofía deweyana de la tecnología, un interés que está eclipsando la ya célebre reapropiación rortiana de la obra de Dewey. Hickman es además director del Center for Dewey Studies en Carbondale, Illinois, y autor de la edición electrónica de las obras completas de John Dewey, de la que este mismo trabajo se ha servido. Mi propio derrotero intelectual debe tanto a Larry Hickman que cualesquiera palabras de agradecimiento público son irremisiblemente insuficientes. 
parecen explicar esa omisión, entre las cuales hay que destacar el hecho de que Dewey no escribiera un libro completo sobre el tema, sino un buen número de observaciones diseminadas a lo largo de su obra, insertas en textos sobre metafísica naturalizada, ética industrial, democracia pragmatista, lógica experimental, estética naturalista, pedagogía progresista o filosofía de la religión. Aunque esta dispersión dificulte nuestro tratamiento del tema, también apunta algo revelador: la filosofía de la tecnología cumple un importante papel vertebrador en toda la obra de Dewey. Ello puede parecer una exageración, habida cuenta de que el término tecnología (y sus derivados) sólo aparece 371 veces en los 37 volúmenes de las obras completas de Dewey. El siguiente pasaje de Dewey nos ayuda a precisar nuestra observación, al tiempo que nos introduce de lleno en nuestro tema. Tras definir a la ciencia como modo de la tecnología, nuestro autor añade en una nota: "El Dr. Clarence Ayres, hasta donde sé, ha sido el primero en denominar explícitamente a la ciencia como un modo de la tecnología. Probablemente, yo mismo habría podido evitar bastantes malentedidos si hubiese empleado 'tecnología' en vez de 'instrumentalismo' en conexión con mi concepción del rasgo distintivo de la ciencia en tanto que conocimiento."15 (LW 15:89). Este texto (procedente de "By Nature and by Art", un escrito que Dewey publicara en el Journal of Philosophy en 1944) parece prestar plausibilidad prima facie a las siguientes tesis sobre el carácter tecnológico de la ciencia según Dewey. (1) Su teoría instrumentalista del conocimiento científico conlleva la concepción de la investigación como un modo de producción tecnológica. Ello supone, ante todo, (2) una revisión de la jerarquía aristotélica teoría-praxis-poiesis y, en consecuencia (3) relativizar la distinción entre ciencia aplicada y ciencia pura, situándola bajo parámetros socioeconómicos y disolviendo su clásica fundamentación ontológica (el dualismo entre dos regiones de la realidad, inferior y superior, permanente y cambiante, estable y precaria) y epistemológica (la teoría contemplativa del conocimiento, el conocimiento del espectador). De ahí que la concepción deweyana de la ciencia como tecnología esté vinculada

15 Según Hickman (op. cit., p. 2) Ayres fue de los pocos discípulos de John Dewey que supieron ver el alcance de su instrumentalismo como filosofía de la tecnología. Años atrás, en su recensión del libro de Ayres Science: The False Messiah, Dewey ya había destacado notablemente la interdependencia entre ciencia y máquinas: "En realidad, la historia de la ciencia es la historia de la invención y del empleo de máquinas y de una técnica, tan prodigiosa como elaborada, para el uso de instrumentos. La máquina es la realidad de la ciencia; la interpretación teórica puede o no ser verdadera. Al final, la respuesta puede leerse en alguna máquina más sutil, precisa y usada con mayor pericia que la máquina que proporcionó el material sobre el que otras teorias se basaron. La verificabilidad de las conclusiones científicas significa que no se sostienen solas. Son posibles gracias a las máquinas, y cualquiera que opere planificadamente con ellas obtendrá resultados semejantes. Pero la ciencia empieza y termina en las máquinas" (LW 3:306). 
con (4) una concepción alternativa de la instrumentalidad (basada en lo que Dewey llama continuidad entre medios y fines), con (5) una ontología transformacional (expresada en su lema, de resonancias marxistas, sobre el carácter práctico de la realidad), y con (6) una teoría naturalista-ecológica del conocimiento (expresada en un modelo homeostático y evolutivo de la inteligencia como intervención en un entorno, priorizando así la acción humana dentro de una comunidad biótica). Desarrollaré estos puntos en los epígrafes que siguen.

\section{Teoría y supremacía social}

Apoyándose en la crítica histórica, Dewey —y en esto no es original- atribuye la primacía de la teoría a la supremacía social de una casta ociosa. La etimología griega de la palabra parece apuntar a la casta sacerdotal, pues theorein significa tanto contemplación de Dios como desfile religioso. En todo caso, la posesión de la teoría parece legitimar la desigualdad social, como muestra el siguiente fragmento del primer capítulo del libro Alfa de la Metafísica de Aristóteles: "Y si afirmamos verdaderamente que los directores de obras tienen más derecho a nuestro respeto que los simples operarios [...] La superioridad de los jefes sobre los operarios no se debe a su habilidad práctica, sino al hecho de poseer la teoría y conocer las causas" (981b). La propia reconstrucción aristotélica de la historia de la filosofía anterior a él revela una jerarquía en ese conocimiento de las causas. Las causas materiales y eficientes (de las que, en principio, se ocuparía el operario) ocupan un lugar inferior a las formales y finales (de las que se ocupa el verdadero jefe, el teórico). Según Dewey, ello corresponde grosso modo a un dualismo ontológico entre la esfera del ser -el mundo atemporal e inmutable de las naturalezas esenciales de las cosas, cuya contemplación es prerrogativa del teórico ocioso- y la esfera del devenir - o mundo sublunar, si se quiere, inestable, cuya manipulación o alteración es cosa de técnicos y artesanos. A este dualismo habría que añadir otra división: la división aristotélica, presente en el libro I de su Física, entre seres que son por naturaleza (physis) y seres que son por artificio (techné), además de una cualificación: junto a la physis, Aristóteles también señala a los artificios, y en particular a los títeres y autómatas, entre las cosas dignas de admiración y asombro, primeros motores de la ciencia (Met. 983a). Esta cualificación no es banal, pues quizá apunte ya un hecho que también Heidegger puso de manifiesto: ${ }^{16}$ los griegos ya iniciaron una comprensión técnica de lo físico. Pero varias décadas antes que Heidegger, Dewey señalaba la ingratitud de

16 Véase M. Heidegger, La pregunta por la técnica, Odós, Madrid, 1996, p. 9. Véase también Félix Duque, Filosofía de la técnica de la naturaleza, Tecnos, Madrid, 1987, pp. 149 y ss. 
los fílósofos griegos hacia los artesanos, de quien "tomaron prestados" sus modelos al tiempo que, ocultando el préstamo, envilecieron a los técnicos a la condición de puros medios. Cito a Dewey, en Experiencia y naturaleza:

La división social entre una clase trabajadora y una clase ociosa, entre la industriosidad y la contemplación estética, devino en una división metafísica entre cosas que son puros medios y cosas que son fines. Los medios son algo menor, abyecto, digno de esclavos; los fines son algo de porte liberal y final; las cosas como medios testimonian su inherente defectuosidad, su dependencia, mientras que los fines testimonian su ser independiente e intrínsecamente autosuficiente. De manera que los primeros jamás pueden ser conocidos en sí mismos, sino sólo mediante su subordinación a objetos que son finales, mientras los últimos pueden ser conocidos en y por sí mismos mediante una razón cerrada en y por sí misma. $Y$ así la identificación del conocimiento con la contemplación estética y la exclusión de la ciencia del ensayo, el trabajo y la administración de las cosas se convierte en una sola y misma cosa. La ingratitud que los pensadores mostraron hacia los artistas, quienes gracias a la creación de objetos compuestos armoniosamente depararon a la filosofía idealista modelos empíricos para sus objetos verdadera y exclusivamente reales, fue mayor si cabe cuando de los artesanos se trataba. Los resultados acopiados a partir de las observaciones de agricultores, navegantes y albañiles proporcionaron una información fáctica y objetiva sobre los acontecimientos naturales, pero también depararon el patrón de subordinación lógica y metafísica del cambio [...]. Mientras que los pensadores condenaban a la clase industrial y despreciaban el trabajo, tomaron prestados de una y otro los hechos y las concepciones que daban forma y sustancia a sus propias teorías. Pues fuera de los procesos del arte no había base alguna para incorporar la idea de logro, de realización, en una noción de fin, ni para interpretar las operaciones antecedentes como potencialidades. (LW 1:90, $102,103)$

Líneas después, Dewey habla de la fatal separación que esta concepción griega llevó a cabo entre lo instrumental y lo final (entre medios y fines). La concepción deweyana de la ciencia como tecnología se inspira a partir del rechazo de esa separación y, por ende, en una nueva concepción de la instrumentalidad. Una vez redefinida la instrumentalidad, no hay ningún problema en ubicar a Dewey entre las versiones instrumentalistas de la tecnología de las que Borgmann ${ }^{17}$ hablaba. Donde no es posible ubicarlo

17 Véase A. Borgmann, Technology and the Character of Contemporary Life, The University of Chicago Press, Chicago, 1987, pp. 7 y ss. Por lo demás, y pese a su concepción severamente crítica de la tecnología, Borgmann comparte los presupuestos teoreticistas y nomológicodeductivos de los que hablábamos al comienzo del artículo. De hecho llega a instituir una explícita correlación entre el explanandum de la teoría y un supuesto transformandum de la tecnología, op. cit., p. 27. Agradezco a Edna Suárez y Sergio Martínez sus sugerencias al respecto. 
es entre las concepciones sustancialistas. El rechazo de Dewey a estas últimas es explícito, como demuestran sus críticas a Mumford y Spengler. ${ }^{18}$ Pero pasemos a explicar brevemente esa concepción de la instrumentalidad propuesta por Dewey.

\section{La concepción orgánica de la instrumentalidad}

Según Dewey, el pensamiento griego, al atribuir realidad a lo final, en cuanto que estable, e irrealidad a lo instrumental, en cuanto que transitorio, evitaba al menos esa identificación de la instrumentalidad con la pura conveniencia subjetiva propia de buena parte de la filosofía moderna - ejemplarmente encarnada, en mi opinión, en la tesis weberiana del "desencantamiento" anejo a los procesos de racionalización tecnológica, tesis de considerable influencia en autores germanos que, en los deprimentes años que siguieron a la derrota alemana en la Primera Gran Guerra de aniquilación tecnológica y al Diktat de Versalles, hicieron del nihilismo el punto central de sus filosofías de la tecnología: me refiero no sólo a Spengler, sino a Martin Heidegger, Ernst Jünger, Carl Schmitt y Gottfried Benn, entre otros autores más o menos vinculados a la llamada revolución conservadora durante la República de Weimar. El concepto de desencantamiento del que hablaba Max Weber y que hacía referencia a la desintegración del orden axiológico del mundo, es heredero de una concepción kantiana de la instrumentalidad que independiza los fines de los medios. Poco importa que Weber invierta la situación kantiana y desprovea de racionalidad al reino de los fines para restringirla al ámbito de los puros medios, de la instrumentalidad burocrática. Pero lo relevante aquí es que, tanto en la concepción griega como en la moderna, los fines están dados de una vez por todas, bien sea por la

18 "La ciencia, la tecnología, la conquista industrial de la naturaleza, no son fuerzas impersonales cuyo desarrollo sea independiente de nosotros. Son lo que los seres humanos hacen con y a partir de ellas. Nadie ignora que los instrumentos, las maquinarias, los aparatos de descubrimiento científico, fueron inventados y construidos por seres humanos para implementar su conocimiento. Lo que no hemos visto es que la dirección en la que se mueven tras haber sido inventadas, junto con las consecuencias sociales que producen, son también un asunto humano y responsabilidad humana. Los debates sobre la posibilidad y la deseabilidad de una planificación humana olvidan a menudo el hecho de que rehusar a hacer lo mejor que podamos a la hora de planificar significa rehuir de la responsabilidad que los acontecimientos nos han impuesto" (LW 17:452). "Pero la destrucción total de todos los elementos de la civilización por culpa de la tecnología y las máquinas sólo será posible si el resto de nosotros — desde la cotidianidad, más que desde un sentimiento trágico- coincidimos con Spengler en que el pensamiento y los deseos humanos son impotentes. De poco sirve afirmar que estamos bajo el mando absoluto de una fuerza cósmica arrolladora, cuando el problema al que en realidad nos enfrentamos es qué hacer con las herramientas que nosotros mismo hemos creado" (LW $6: 285)$. 
verdadera naturaleza de las cosas, por el puro interés subjetivo del individuo aislado o por el desinterés objetivo de la humanidad racional.

Dicha concepción de la instrumentalidad es nefasta para Dewey, y en primer lugar porque en ella se ha realizado una hipóstasis de los fines. Se incurre así en lo que Dewey llama la falacia filosófica por excelencia: convertir el resultado de un proceso temporal en una realidad inmutable y metafísicamente antecedente a dicho proceso. Y lo que es peor, la escisión, la discontinuidad entre los fines y los medios, imposibilita la producción de nuevos fines, orientaciones y sentidos, según Dewey.

Esta concepción hipostasiada de los fines y residual de la instrumentalidad es la que tradicionalmente ha sido conocida como instrumentalismo sin más: no importa que los fines sean verdad revelada, legado de la tradición o código convencional. En cualquier caso, los fines son algo en cuya definición no participan los medios por los que, en teoría, se alcanzan. Esta instrumentalidad es cuando menos espuria: ¿qué tipo de fines son aquellos que pueden especificarse sin hacer referencia a los procesos que a ellos posiblemente conduzcan? Si digo que $x$ es un fin (por no hablar de la verdad, la bondad o la belleza, fines tradicionalmente filosóficos), ¿no he de tener ya confeccionado un mapa cognitivo de en qué consistiría alcanzar ese fin, i.e., qué medios me conducen a él? A este tipo de fines temporalmente especificables, los llama Dewey fines a la vista (ends-in-view). Y a la concepción de la instrumentalidad que se apoya en ellos, la hemos llamado orgánica: Una instrumentalidad genuina para un fin es siempre un órgano de ese fin (LW 1:276).

Que medios y fines sean para Dewey partes de un continuo orgánico es otra manera de decir que medios y fines han de definirse recíprocamente - precisamente porque nuestros fines no están predeterminados. Precisamos cuál era el objeto de nuestra acción en el proceso, es decir, imaginando rutas que nos permiten dar contenido a un fin apenas bosquejado.

Así pues, la racionalidad es para Dewey una cuestión de medios y de consecuencias. Si hemos de entender medios como medios constitutivos internos y fines como fines a la vista, lo que hemos llamado concepción orgánica de la instrumentalidad articula conceptualmente las distintas manifestaciones de la racionalidad. Y si, según Dewey, la tecnología se aproxima a las cosas y eventos en sus potencialidades e instrumentalidades, esto es, en su función como medios y "signos predictivos" de ulteriores eventos y cosas, la racionalidad se manifiesta tecnológicamente desde un principio en el control de esos signos. Ya hemos visto cómo en la concepción tradicional de la instrumentalidad subyace una racionalidad formal e hipostasiada. Para Dewey es ésta la que aliena, la que atrofia la capacidad humana de contro- 
lar su experiencia. ${ }^{19}$ Tecnología es para Dewey otro rubro para ese control inteligente como condición de significatividad de la experiencia. Dicho sea con otras palabras: es la transformación de la experiencia en arte, de las causas en medios y de los efectos en consecuencias, de manera que las cosas cobren sentido.

No resulta difícil hallar aquí una versión naturalizada del principio de significación verificacionista: ser significativo es tener consecuencias. Con todo, la historia nos enseña que no hay un conjunto cerrado de métodos de verificación, de procedimientos de efectuación de consecuencias. Y ya que ese control inteligente no es una cuestión algorítmica, es inútil tratar de generar la producción de experiencias con nuevos sentidos y valores sin experimentación: sin averiguar los límites o restricciones de las situaciones materiales en las que nos hallamos inmersos, para explorar y desarrollar aquellas potencialidades que podrían llevar a efecto los fines a la vista dentro de esos límites. A este arte de la experimentación lo llama Dewey investigación y a su carácter experimental tecnología. Esa identificación es posible tras un periodo en el cual el conocimiento natural progresaba gracias a los préstamos de las artesanías industriales y la ciencia entró en un proceso de crecimiento gracias a la invención deliberada de instrumentos. "Y para distinguir este rasgo diferencial del arte científico, emplearé la palabra tecnología" (LW 15:89).

\section{Conocer y transformar la realidad}

En efecto, según Dewey, la ciencia empieza a ser tecnología en el momento en que deja de ser concebida como un conocimiento "por naturaleza" para ser asimilada a un conocimiento "por arte"; ello ocurre tras la revolución científica de los siglos xvi y xvil, cuando la experiencia es transformada en experimentación, convirtiendo las antiguas dualidades cosmológicas y ontológicas en distinciones metodológicas. La diferencia entre las verdades de la ciencia y las opiniones del sentido común son estrictamente metodológicas. Si para el mismo Quine, siguiendo una tradición que va de Hegel

19 Sirva el siguiente texto de Dewey como réplica a las críticas de Horkheimer que hacen de la racionalidad deweyana una razón subjetiva y entregada. No hay mayor entrega que la de la renuncia al control: "La razonabilidad o racionalidad, es, según la postura aquí adoptada, al igual que en su uso ordinario, una cuestión de medios y consecuencias. Cuando nos proponemos fines no resulta sensato adoptar aquellos que no guardan conexión con medios disponibles ni tampoco es razonable proponérnoslos sin referencia alguna a los obstáculos que hayan de levantarse en su camino. Resulta razonable buscar y escoger aquellos medios que, con el máximo de probabilidad, acarrearán las consecuencias que tenemos en vista [...]. La racionalidad, como concepto abstracto, no es más que la idea generalizada de la relación medios consecuencias como tal. [.. .] Pero la racionalidad ha sido hipostasiada" (LW 12:18). 
a Neurath, la ciencia es sentido común autoconsciente, ${ }^{20}$ Dewey dotará a ese proceso de autoconciencia de un carácter explícitamente tecnológico: "Potencialmente, los objetos de estudio de la sensibilidad y de la opinión son ciencia en proceso: son su materia prima. El perfeccionamiento de los procedimientos y de las técnicas de investigación transformarán su material en conocimiento científico" (LW 15:85). Ahora bien, y como sabemos, ninguna transformación es definitivamente inmune a la obsolescencia: no hay objeto de conocimiento científico que permanezca para siempre y no esté sujeto a revisión gracias a mejores procedimientos heurísticos. La revolución científica fue debida en parte a la sustitución del conocimiento por naturaleza por el conocimiento por arte:

La conexión no es ni remota ni recóndita. Las artes tiene que ver con la producción, con la generación, con hacer y construir. Caen pues en el dominio de cosas que en el esquema clásico son mutables, de las cuales, según tal esquema, no hay conocimiento posible. Pero de acuerdo con la forma en que hoy se conduce la ciencia y de acuerdo con sus conclusiones, ésta consiste en el conocimiento de órdenes de cambio. (LW 15:85)

Reparemos en la imagen tecnológica con la que Dewey ejemplifica la continuidad entre sensibilidad/sentido común y ciencia: el objeto del primero es la materia prima de la segunda, cuyos métodos y técnicas lo transformarán en conocimiento científico. Esa transformación es "por arte", en el sentido de "arte de control", como ya titulara Dewey a uno de los capítulos de La búsqueda de la certeza, o como control de variables: cuando el objetivo del conocimiento son las correlaciones entre los cambios, obtenemos un instrumento para controlar esos cambios. Dado un cambio, y conociendo métricamente su conexión con otro cambio, está en nuestras manos la posibilidad de producir o evitar este cambio. La actitud de control, comenta Dewey, mira al futuro, a la producción. Para esa producción de consecuencias es necesario llevar a cabo una selección de condiciones y parámetros relevantes. El reconocimiento explícito de esa selección es una de las principales virtudes epistémicas, la marca de honestidad intelectual en la ciencia. Lo dado no es tanto "dado" (given) como "tomado" (taken).

La producción de consecuencias y el control en la transformación forman parte de la definición de investigación propuesta por Dewey: "La investigación es la transformación controlada o dirigida de una situación indeterminada en otra tan determinada en sus distinciones y relaciones constitutivas que convierte los elementos de la situación original en un todo unificado" (LW 12:108).

20 Véase W.V.O. Quine, Palabra y objeto, trad. de M. Sacristán, Labor, Barna, 1968, p. 17. 
Es difícil entender esta definición de investigación con independencia de la ontología transformacional que comporta. He adelantado que esta ontología transformacional tiene resonancias marxistas. Recordemos que, en Las tesis sobre Feuerbach, Marx señala que el problema de la verdad objetiva tiene un carácter marcadamente práctico. En mi opinión, Dewey es más radical que Marx: la misma realidad tiene un carácter práctico.

Dewey caracteriza la situación indeterminada de la que parte la investigación en términos objetivos, y no en términos de una incertidumbre cartesiana, subjetiva o psicológica. Retoma así de Peirce la idea de que la inteligencia sólo puede operar en la contingencia. Karl Popper ha sugerido un modo de interpretar ecológicamente esa incertidumbre objetiva que, en principio, es afín a la que Dewey desarrolló en su Lógica:

La emergencia de una nueva situación problemática podría considerarse como un cambio o diferenciación del "nicho ecológico" o del medio relevante para el organismo. (Tal vez pueda denominarse selección del hábitat [...] el hecho de que cualquier cambio en el organismo o en sus hábitos o en su hábitat produzca nuevos problemas explica la increíble riqueza de las soluciones (siempre provisionales). ${ }^{21}$

Lo decisivo aquí es que la "irritación" que produce la duda y que pone en marcha la investigación no tiene su origen en un déficit cognitivo, entendido como una especie de indecisión entre opciones alternativas. Las discusiones al uso sobre decisión racional en la ciencia suelen estar sesgadas hacia la ciencia como teoría explícita y no como práctica.

Cuando nos centramos en las prácticas científicas, es más fácil reparar en que no hay una solución antecedente, ready-made, sabida de antemano (desde el punto de vista del Ojo de Dios, que diría Putnam) a la que la investigación tienda. Es la propia investigación la que crea o construye la solución,

21 K. Popper, Conocimiento objetivo, trad. de Carlos Solís, Tecnos, Madrid, 1974, p. 226. En Experiencia y naturaleza, la metafísica naturalista de Dewey da un sentido fuertemente ontológico a la indeterminación ecológica de la situación. Allí, la existencia es para Dewey un compuesto mixto de determinación e indeterminación, de predictibilidad y aleatoriedad, de certidumbre e inseguridad, de vigencia y obsolescencia, de estabilidad y precariedad. Es el psicólogo James Gibson quien nos ofrece una versión ecológica de los conceptos de precariedad y estabilidad mucho más creible y menos estridente a oídos contemporáneos: "El entorno manifiesta por lo general cosas permanentes y cosas que no lo son, rasgos invariantes y rasgos variantes. Un entorno absolutamente invariante, inerte y de partes absolutamente invariantes, sería algo absolutamente rígido y, obviamente, ya no sería un entorno. De hecho, ya no habría ni animales ni plantas. En el otro extremo, un entorno cuyas partes cambian en su totalidad y donde sólo hay variación, un entorno consistente en nubes y enjambres de materia, tampoco sería un entorno" (J. Gibson, An Ecological Approach to Visual Perception, Lawrence, Nueva Jersey, 1986, p. 269). Debo a la lectura del libro de Tom Burke, Dewey's New Logic (Chicago University Press, Chicago, 1994) la conexión Gibson-Dewey. 
encarnada en un juicio. De ahí que Dewey conciba la investigación como un proceso tecnológico desde un principio. En mi opinión, esta concepción tecnológica del conocimiento permite reinterpretar su hegelianismo: entendida dentro de la ontología transformativa del pragmatismo americano, la tesis hegeliana "todo lo real es racional" supone inevitablemente la realidad de la racionalidad, su causalidad inmanente: lo racional es (inseparable de) lo real porque, por así decirlo, la razón crece endógenamente en el tejido de la realidad. Para Hegel, por ejemplo, los instrumentos técnicos son la encarnación material de la razón. ${ }^{22}$

Dicho de otro modo: desde el momento en que interviene, el conocimiento, la investigación, transforma existencialmente la realidad, entretejiéndose en su red. Para Dewey, la idea hegeliana de que el conocimiento altera o transforma lo conocido no es en absoluto objetable, pues Dewey convierte la primacía hegeliana de la praxis en el carácter abiertamente práctico de la realidad: "por pragmatismo entiendo la doctrina de que la realidad tiene carácter práctico, perfectamente expresado en la función intelectiva [...] el conocimiento es la realidad ejecutando determinadas transformaciones en sí misma" (MW 4:128). Para Hegel el conocimiento no era sino el proceso mismo por el que la realidad se transforma de acuerdo con una lógica dialéctica. Sustituyamos conocimiento por investigación y lógica dialéctica por tecnología y nos hallaremos cerca de una definición de investigación como la propuesta por Dewey.

Resulta sorprendente la caracterización tecnológica que Dewey realiza del pensamiento: "el pensamiento no es en esencia distinto del uso de energías y materiales naturales, digamos del fuego y de herramientas, para refinar y reordenar y configurar otros materiales naturales $[. .$.$] pensar es un$ proceso continuo de re-organización temporal" (LW 1:61). Pensar es pautar, producir el significado en la experiencia: reorganizar la experiencia de manera que unas cosas evidencien otras. Contamos para eso con el lenguaje, una metaherramienta que aumenta exponencialmente nuestra capacidad

22 De ahí que denominar al instrumentalismo naturalista de Dewey hegelianismo naturalizado no me parezca un precio demasiado alto. Lo mismo cabría decir de Marx y de su inversión/naturalización del hegelianismo. La siguiente nota de El capital es bien significativa: "Una historia crítica de la tecnología demostraría en qué escasa medida cualquier invento del siglo xvil se debe a un solo individuo. Hasta el presente no existe esa obra. Darwin ha despertado el interés por la historia de la tecnología natural, esto es, por la formación de los órganos vegetales y animales como instrumentos de producción para la vida de plantas y animales. ¿No merece la misma atención la historia concerniente a la formación de órganos productivos del hombre en la sociedad, a la base material de toda organización particular de la sociedad? [...] La tecnología pone al descubierto el comportamiento activo del hombre con respecto a la naturaleza, el proceso de producción inmediato de su existencia, y con esto, asimismo, sus relaciones sociales de vida y las representaciones intelectuales que surgen de ellas" (El capital, cap. XIII, nota 89, Fondo de Cultura Económica, México, 1974, p. 453). 
de control instrumental: "Como ser una herramienta, o ser usado como un medio para unas consecuencias, es tener y dar significado, el lenguaje, siendo la herramienta de las herramientas, es la madre al cuidado de toda significación" (LW 1:147). Como ya adelantaba, el significado para Dewey es un método de acción: "los significados son reglas para usar e interpretar las cosas, siendo la interpretación siempre una imputación de potencialidad para algunas consecuencias" (LW 1:147).

Con el manejo simbólico la interpretación deviene en transformación de unas fases temporales de la experiencia en signos de otras: en predicciones y retrodicciones. Cuando realizamos una inferencia de una de estas fases a otras, cosas y eventos aparecen en la experiencia como inevitablemente instrumentales y potenciales, como una serie de cualidades tratadas como potencialidades que tienen específicas consecuencias existenciales. Atribuimos propiedades a los objetos formando proposiciones cuyos predicados involucran condicionales contrafácticos: son operadores disposicionales o imputaciones transfactuales ${ }^{23}$ que indican posibles operaciones, cursos de acción por seguir, disposiciones. Éstas son potencialidades e interacciones y, por tanto, cambios o transformaciones. El objeto no es otra cosa que una serie de transformaciones sistemáticas en correspondencia funcional: un haz de correlaciones que hacen que la experiencia adquiera significación, que gane potencialidades. "Cuando un evento tiene significado, sus potenciales consecuencias se convierten en su rasgo principal. Cuando éstas resultan importantes y se repiten, forman la verdadera naturaleza y esencia de la cosa, su forma definitoria, su carácter idéntico y distintivo y [...] como significado, las consecuencias futuras ya pertenecen a la cosa" (LW 1:143).

Concluyo aquí mi exposición del carácter tecnológico de la ciencia en John Dewey. En los puntos que restan, intentaré dar cuenta de algunas de sus ventajas a la hora de abordar ciertos problemas de la filosofía de la ciencia: la cuestión de la convergencia, la causalidad, la distinción entre lo conceptual y lo fáctico. Por último, ubicaré la filosofía de la tecnología de John Dewey como crítica de la cultura a partir de su redefinición de la relación entre la ciencia y sus aplicaciones.

\section{Práctica científica y tecnología}

\section{(1) Causalidad y eficacia causal}

De todas las razones aducidas para justificar la existencia de nexos causales, la eficacia causal del trabajo industrial y la práctica e instrumentación

23 El término es de Nicholas Rescher, en La primacía de la práctica, trad. de A. Sánchez, Tecnos, Madrid, 1970. 
experimentales es para Dewey la más acertada. En La reconstrucción en la filosofía y La búsqueda de la certeza, la explicación deweyana se halla bajo la influencia de la antropología, en particular de los estudios sobre cultura material, basando ésta en el control de las relaciones de causa y efecto y la transmisión histórica de esos procedimientos de control.

Siguiendo una sugerencia de Ludwig Feuer, quien señala que los empiristas estuvieron menos involucrados en la construcción de artefactos tecnológicos que los racionalistas, podríamos aventurar que la firmeza de la creencia en nexos causales por parte de los racionalistas (frente al clásico escepticismo británico) se debe a sus trabajos tecnológicos. Leibniz trabajó en tecnologías eólicas como fuerza motriz para la minas de Harz, y sabemos que Spinoza era pulidor de lentes e ideó varios instrumentos ópticos. Más allá de esta sugerencia, Dewey vincula convincentemente trabajo, tecnología y causalidad.

La creencia en el principio de causación ha recibido razones extraordinarias y sutiles. El trabajo y el uso de instrumentos parecen constituir, sin embargo, una razón empírica suficiente: de hecho, son los únicos acontecimientos empíricos que pueden apuntar de manera específica hacia esa conexión. Como bases para la aceptación de la creencia en la causalidad, son más adecuadas que las secuencias regulares dé la naturaleza o que cierta categoría de la razón o el supuesto hecho de la voluntad. El primer pensador que proclamó que cualquier evento es efecto de algo y causa de alguna otra cosa, que cada existencia particular es tanto una condición como algo incondicionado, se limitó a consignar por escrito los procedimientos del artesano, convirtiendo un modo de la práctica en una fórmula. La regularidad externa es algo que nos resulta tan familiar y rutinario que damos por sentado sin detenernos a pensar en ello. La regularidad, la secuencia ordenada, se presenta al pensamiento en el trabajo como un principio de control. Las artes industriales son formas-tipo de la experiencia que traen a la luz las conexiones secuenciales de las cosas entre sí. (LW 1:74)

La causalidad como problema ontológico o epistemológico sólo surge cuando olvidamos que el establecimiento de cadenas causales nunca es final ni completo, sino que es un medio para determinar una situación previamente indeterminada. El juicio, el fin de la investigación, refiere a esa situación determinada. Las proposiciones, empíricas o conceptuales, son los medios para llegar al juicio.

\section{(2) Lo conceptual y lo empírico}

Uno de los rasgos más característicos del pragmatismo es su insistencia en que ningún juicio es irrevisable. Ese mismo falibilismo comporta una característica importante de la teoría deweyana de la investigación: la diferencia 
entre proposición y juicio es funcional y temporal. Como dice Dewey, las proposiciones "se proponen, se afirman, se enuncian", mientras que los juicios se "sientan, se establecen". Las proposiciones son medios para el juicio. En este sentido, las proposiciones "fácticas" iniciales son un medio, una premisa, un recurso para formular el problema; dicho sea con otras palabras: ayudan a establecer por qué la situación indeterminada representa un problema. Según Dewey, las proposiciones fácticas o materiales contribuyen a la formación del sujeto del juicio. ${ }^{24}$ Su contenido material es intermedio o representativo; en este sentido constituye su contenido judicable: lo que aún no es juicio.

Ahora bien, la misma formulación de un problema anticipa ya el parámetro de relevancia o significatividad de posteriores hipótesis. Esta anticipación cobra en Dewey la forma de "sugerencias" o ideas. La distinción entre hechos e ideas es por tanto puramente operacional. En "La lógica de la verificación", un artículo de juventud, podemos hallar una formulación más falibilista de la tesis fregeana de que un hecho es un pensamiento verdadero, ${ }^{25}$ y lo hace teniendo en cuenta el proceder efectivo de la ciencia en la formulación de hipótesis. Según Dewey, la mente articula una hipótesis o teoria porque le insatisfacen algunos de los juicios que mantiene. Las ideas que en un principio fueron tomadas como hechos, acaban cayendo bajo sospecha:

La hipótesis es una idea que se supone que es un hecho, o como mínimo, algo más próximo a un hecho que las ideas previas. Pero, en tanto se halla bajo verificación, se sostiene sólo de manera tentativa y en muy distintos grados de seguridad comparativa [...] El proceso de transformar la hipótesis, o la idea sostenida sólo como tentativa, en un hecho, o idea sostenida definitivamente, constituye la verificación. (EW 3:87)

Según Dewey, ningún hecho aislado puede ser considerado una prueba, cosa que implica ya el carácter operacional de "hechos" e "ideas". Sugiero que ello permite eludir lo que Davidson llamó el tercer dogma del empirismo (la distinción entre esquema conceptual y contenido). Como Davidson, Dewey reniega de un tertium quid:

24 Aunque la distinción entre juicio y proposición es importante, resulta algo anacrónico llevarla a cabo sobre una estructura Sujeto-Predicado tras los modernos desarrollos de la lógica matemática. En este punto, creo que muchos de los críticos de Dewey tienen razón. Debo esta observación a mi discusión con Sergio Martínez, Carlos Pereda y Douglas MacDermid en el Seminario Conocimiento y juicio, celebrado en el Seminario del Departamento de Filosofía de la Universidad Autónoma del Estado de Morelos, Cuernavaca, en febrero de 1999.

25 "El hecho es la idea a la que nada contradice, que armoniza con otras ideas, que permite el libre juego y la economía de movimientos de la mente. En un principio, idea es un hecho que sentimos nos depara dificultades, que opone una mínima resistencia a la mente" (EW 3:86). 
La fórmula kantiana según la cual, consideradas independientemente, "las percepciones son ciegas y los conceptos son vacíos", no carece de cierta penetración lógica, la cual, sin embargo, sufrió una radical distorsión en tanto que concedía de antemano que los contenidos conceptuales y perceptivos tenían diferente origen y, por ende, se requería una tercera actividad, la del entendimiento sintético, para aunarlas. En términos lógicos, los contenidos perceptivos y conceptuales quedan instituidos funcional, correlativa y recíprocamente, de tal manera que los primeros ubican y describen el problema, mientras que los últimos representan un posible método de solucionarlo. (LW 12:115)

Llegamos así a la construcción del predicado del juicio: los contenidos ideacionales tienen el carácter operacional de posibilidades, de sentidos que han de ser encarnados en símbolos. El razonamiento discursivo es esa fase de la investigación en la que llevamos a cabo operaciones conceptuales. El desarrollo del contenido semántico de las ideas en sus relaciones mutuas, lo que en términos lógicos podríamos llamar entrañamiento semántico o derivabilidad formal es, según Dewey, un proceso lógico que opera con símbolos. Las conectivas lógicas representan esa relación: la proposición no es otra cosa que la formulación simbólica de esa relación entre sentidos, contenidos operacionales o posibles soluciones. Pero, por sí misma, la coherencia semántica puede conducirnos a una engañosa plausibilidad a priori que dé por terminada la investigación, bloqueándola, como ya señalara Peirce. Un auténtico predicado ha de ser disposicional, esto es, ha de conducirnos a un método de verificación. Y para Dewey, como para Quine, no hay método a priori de verificación, "no matter what". Los contenidos ideacionales del predicado han de anticipar una solución factible.

De ahí que esta caracterización funcional de los contenidos ideacionales y semánticos de una hipótesis haya de ser completada con el requisito de aplicabilidad existencial o material: el contenido judicable de una hipótesis ha de conducir a un experimento. Frente a la operación conceptual, Dewey llama a esta operación "tecnológica": una operación conducente a lo que Hacking llama "la creación de un fenómeno". El predicado de un juicio ha de ser la concreción experimental o predictiva de un haz de disposiciones, esto es, de posibles comportamientos del sujeto juzgado: de la situación que se intenta resolver mediante la investigación. La resolución final de ambas operaciones, conceptual y tecnológica, es una situación o, si se quiere, una situación transformada, "determinada". Pero su determinación es sólo temporal, provisional (LW 15:85).

\section{(3) Convergencia y falibilismo}

En este punto, la diferencia entre Peirce y Dewey es radical. Peirce acabó por apelar a una idealizada cosmología evolutiva para evitar cierto relativismo 
epistemológico, explicando la diferencia entre verdad y justificación en su teoría de la verdad como convergencia ideal. La realidad era el objeto representado por ese juicio límite ideal al que los juicios de los investigadores convergen, según su célebre definición:

Diversas personas pueden partir desde puntos de vista completamente antagónicos, pero el avance de la investigación los lleva, en virtud de una fuerza extrínseca a ellos, a la misma y única conclusión. Esa actividad del pensamiento que no nos lleva a donde queremos sino a una meta preordenada es como la operación del destino [...] La opinión que está destinada a ser el punto de convergencia de todos los que indagan es aquella a la que nos referimos al hablar de verdad, y el objeto representado por esta opinión es el real. Ésta es mi forma de representar la realidad. ${ }^{26}$

Dewey no necesita recurrir a ese supuesto cosmológico para eludir la acusación relativista: la realidad objetiva de la ciencia se va construyendo tecnológicamente (y no representándose) en el proceso de investigación. Creo que la preferencia deweyana por el término "asertibilidad garantizada" frente a "verdad" puede explicarse por su pertinaz falibilismo: el objeto final de una investigación, una situación determinada, puede convertirse en otra situación indeterminada que propicie ulteriores transformaciones. En qué medida lo sea o no depende de máximas pragmáticas. La siguiente formulación deweayna anticipa sin duda el holismo quineano y su máxima de la mutilación mínima:" "En la investigación, el criterio de lo que se considera como asentado, o como conocimiento, consiste en que se tiene por establecido de tal modo que puede ser empleado como un recurso en una investigación ulterior; el no estar sujeto a revisión en una investigación ulterior" (LW 12:16).

\section{(4) Ciencia pura y ciencia aplicada}

Quizá el más célebre defensor de la tecnología como ciencia aplicada sea Mario Bunge, ${ }^{28}$ pero han sido muchos los que, de un modo $u$ otro, han respetado la distinción entre conocimiento científico puro y ciencia aplicada. La premisa oculta en esta distinción es una dicotomía que posee cierto

26 Ch. S. Peirce, "How to Make Our Ideas Clear", Popular Science Monthly, XII, 1878, p. 296. Christopher Hookway, (Peirce, Cambridge, Londres, 1985, p. 262), cita un texto de Peirce donde esa cosmología absolutista es bastante evidente: "un elemento de puro azar permanece en cada momento, y permanecerá hasta que el mundo se convierta en un sistema racional, perfecto, absolutamente simétrico, en el cual por fin cristalizará la mente en un futuro infinitamente distante".

27 Véase W.V.O. Quine, Pursuit of Truth, Harvard University Press, Cambridge, 1990, p. 15.

28 Cfr. M. Bunge, "Technology as Applied Science", Technology and Culture, no. 7, 1966. 
sesgo kantiano: la ciencia como conocimiento y la ciencia como actividad. ${ }^{29}$ Dewey insiste en que ese dualismo es pernicioso.

Desde un punto de vista pragmático, las prácticas están presentes desde un principio, y es precisamente su presencia la que hace posible cualquier aplicación. La palabra "aplicación" suele sugerir fines o usos de cierto instrumento externos o ajenos a su naturaleza. Pero para Dewey aplicación de la ciencia ha de significar aplicación en la ciencia: "aplicación en algo significa una interacción más extensiva de eventos naturales entre sí, propiciar oportunidades para interacciones que revelan potencialidades previamente ocultas [...] la ingeniería, la medicina, las artes sociales efectúan relaciones que no estaban realizadas en las existencias fácticas" (LW 1:129). En la propia dicotomía entre teoría pura y aplicación yace la objeción a "lo aplicado": lo limitado de su aplicación, su restricción al beneficio privado y las ventajas de clase (sic). Para Dewey la identificación de aplicación con comercialización refleja estrechez de miras, intereses y motivaciones: en resumen, un estrecho reino de fines económicos de clase. E incluso la condena de la ingeniería por parte de los científicos teóricos, por bienintencionada que sea, perpetúa ese reflejo: en este caso de una manera peligrosa para la misma ciencia que practican y para la propia vida humana. ${ }^{30}$ De ahí el interés de Dewey en superar esa desafortunada caracterización mercantilista de lo que es aplicación, partiendo de una caracterización del conocimiento menos transmundana: la aplicación como comprensión efectiva de los eventos existentes, o, en términos más hegelianos, el ingreso de la razón en el mundo mediante transformación controlada de la existencia que hace que dicha razón se sienta "como en casa" (at-homeness) ${ }^{31}$

En El público y sus problemas, Dewey profundiza en las consecuencias de una noción extrínseca de aplicación, lamentándose de que la ciencia se aplique más $a$ la vida que en la vida. El texto es buena muestra del sentido de crítica de la cultura que la filosofía de la tecnología cobra en Dewey:

${ }^{29}$ Cfr. M. Fore, “Transformations of the Myth of 'Engineering Science'", Technology and Culture, no. 7, 1988.

30 "Cabría preguntarse si la idea de que la ciencia es pura en el sentido de ocuparse exclusivamente de un reino de objetos separado de los intereses humanos no ha reforzado esta ineptitud moral. Pues, de hecho, ha establecido otro interés de clase, el de una clase aislada de intelectuales y especialistas. Y está en la naturaleza de cualquier interés de clase consolidar y generar otros intereses, ya que la división y el aislamiento en un mundo de continuidades actúan siempre en reciprocidad. La institución aislada de intereses etiquetados como ideales e idealistas suscita y refuerza intereses que carecen de esa cualidad ideal" (LW 1:131).

31 Lo que hace que una proposición sea científica es, según Dewey, su capacidad para hacernos penetrar los fenómenos existentes, su capacidad para depararnos "intellectual athomeness" en las existencias (LW 1:129). Nótese el paralelo con la célebre locución hegeliana del capítulo $\mathrm{V}$ de la Fenomenología del espíritu: con el Renacimiento, la razón ingresa en el mundo y se encuentra a gusto, "como en casa". 
En el presente, la aplicación de la ciencia física es cuestión de aplicación a los asuntos humanos. Esto es, se trata de una aplicación externa, efectuada en vistas a sus consecuencias para una clase de propietarios con poder adquisitivo. La aplicación de la ciencia en la vida significaría su absorción y distribución, su conversión en una instrumentalidad del entendimiento común y de la comunicación extensiva que constituyen la precondición de la existencia de un público genuino [...] La revolución científica del siglo xvı fue la precursora de la revolución industrial de los siglos xviI y xix. Como consecuencia, el hombre ha sufrido el impacto de un enorme incremento del control sobre las energías físicas sin desarrollar la correspondiente capacidad de autocontrol, de sí mismo y de sus circunstancias. Un conocimiento dividido en su propia contra, una ciencia a cuya incompletud se suma una división artificial, han desempeñado su papel en la esclavización de hombres, mujeres y niños en fábricas en las que se han convertido en máquinas animadas al servicio de máquinas inanimadas. Sórdidas colonias proletarias, empleos frustrantes e inestables, la más absoluta miseria al lado de los más ostentosos lujos, una brutal explotación del hombre y la naturaleza, en tiempos de paz, y bombas explosivas junto con gases nocivos en tiempos de guerra. El hombre, un niño en cuanto a la comprensión de sí mismo respecta, ha puesto en sus manos herramientas físicas de poder incalculable, con las que juega infantilmente. Que provoquen daño o no es algo accidental. La instrumentalidad se convierte así en amo y opera fatalmente como si poseyera una voluntad propia $-\mathrm{y}$ no porque de hecho la tenga, sino porque quien no la tiene es el hombre. La glorificación de la ciencia pura en dichas condiciones no es más que la racionalización de una huida; señala la construcción de un asilo o un refugio, una elusión de responsabilidades. (LW 2:345)

Para Dewey, la concepción restringida de la aplicación genera una noción escindida o residual de instrumentalidad que, a su vez, precipita en una concepción sustancialista de la tecnología como un poder no humano que arrolla al hombre, un pobre aprendiz de brujo, determinando su destino, esto es, dejándolo a merced de consecuencias no deseadas. El desplazamiento al mundo de supuesta "ciencia pura" es pura estrategia transmundana.

En la introducción al último volumen de las obras de Dewey, Sidney Hook señala que sin la evaluación de los efectos de la ciencia y la tecnología sobre la vida social, corremos el riesgo de adaptar nuestros ideales a las consecuencias no deseadas de la aplicación de la ciencia y no a la organización responsable de sus recursos. También Hickman ha titulado el último capítulo de su libro sobre Dewey "Tecnología responsable". No podemos siquiera esbozar aquí cuál es la concepción deweyana de la responsabilidad, entendida como la disposición a asumir consecuencias. Baste decir que, como 
Hans Jonas, Dewey hace también referencia a las "generaciones futuras". ${ }^{32}$ Y, vista la común identificación del pragmatismo con la lógica a corto plazo del capital, resulta cuando menos sorprendente que, hasta donde sé, uno de los primeros filósofos que hizo una clara advertencia de los peligros medioambientales de la sobreexplotación económica de la naturaleza fuera John Dewey. ${ }^{33}$ En un texto significativamente llamado "Libertad" aparecen inequívocamente los términos "restauración" y "generaciones venideras". Todo un anticipo para la problemática ecológica, teniendo en cuenta que fue escrito en 1937.

Permítanme pues acabar este escrito, cuya máxima ambición sería motivar la lectura de la obra de Dewey, con un texto que reivindica la vigencia de la filosofía del pensador de Vermont en una de las facetas más importantes de la crítica contemporánea de la cultura: el pensamiento medioambiental.

Es indudable que el individualismo [...] alentó un desaforado espíritu de especulación que supone un considerable lastre para las generaciones actuales y para las venideras. Impulsó una explotación temeraria y extravagante de los recursos naturales como si fueran literalmente inagotables. Conservar el suelo, restaurar, hacer nuevamente fértiles tierras ya exhaustas, combatir los vertidos y la erosión, que han convertido grandes áreas de nuestro patrimonio natural en algo parecido a un desierto [. . . ése es el precio que hemos de pagar por habernos embarcado indulgentemente en una orgía de supuesta libertad económica. (LW 11:151)

Cuernavaca, Morelos

Recibido: 19 de febrero de 2000

32 Aunque, a diferencia de Jonas, Dewey no apelaría a la idea ontológica de hombre como base para la responsabilidad para con las generaciones futuras. Cfr. Hickman, op. cit., p. 203.

33 Justo es reconocer, no obstante, que F. Engels ya había formulado una advertencia parecida en "El papel del trabajo en la transformación del simio en hombre" (Obras escogidas de Marx y Engels, Londres, 1959, vol. 2, pp. 82-83 y 90). 